\title{
Effects of Dual Tasks on Balance Ability in Patients with Cerebellar Ataxia
}

\author{
Bangsoo Kang, Jin-Hoon Park \\ Department of Physical Education, College of Education, Korea University, Seoul, Korea
}

Purpose: The purpose of this study was to examine the effects of dual tasks on balance and postural control during standing in patients with cerebellar ataxia (CA). It was hypothesized that CA patients would exhibit different sway characteristics of the center of mass (COM) depending on the complexity of the secondary cognitive tasks compared with normal control subjects.

Methods: A total of 8 patients with CA and age-matched healthy control subjects participated in this study. They were instructed to perform two balance tasks (non-dual and dual movement) with 3 different complexity of dual tasks. Range, variability, and velocity of COMs were measured.

Results: According to the results CA patients showed deficits in balance and postural control with increased dual-task complexity during the static balance task in saggital sway movements. However, there was no significant difference in static balance in frontal sway. With higher difficulty in the cognitive task, CA patients took longer to stabilize their body center, while normal control subjects showed no change between conditions. In addition, CA patients had a greater COM resultant velocity during recovery in the dual-task condition compared with the single-task condition. These findings indicate that CA patients had defendable compensatory strategies in performing dual tasks.

Conclusion: In conclusion, CA patients appeared to manage the priority to balance and postural control. Particularly in a situation with a postural threat such as when potential consequences of the loss of stability increase, they appeared to prioritize the control of balance and posture over the performance of the secondary task.

Keywords: Cerebellar ataxia, Attention, Balance

\section{서 론}

신체의 무게중심을 주어진 환경 내에서 평형상태로 유지하는 능력 을 균형이라 하며 일상생활에서 요구되는 모든 동작 수행에 있어서 신체의 안정성과 독립성을 위한 필수 요소라 할 수 있다. 균형을 안정 적으로 유지시키기 위해서는 신체의 감각정보를 통합하고 수집된 감 각정보를 상위수준의 신경계에서 적절하게 처리를 해야 하는 복잡 한 과정이 요구되며 신체무게중심을 기저면 내에 유지시키고 신체의 동요를 최소화시키기 위한 협응적 협력과정을 통해 운동계획과 실행 이 이루어지게 된다. ${ }^{2}$ 균형에 필요한 감각정보 처리는 피드포워드 (feedfoward)와 피드백(feedback)의 관점을 통해 이루어진다. 피드포워 드는 신체에 예상되는 동요의 변화를 예측하여 반응하는 예비적 자 세적응(anticipatory postural adjustment, APA)으로 하지와 체간근육 을 사용하여 신체무게중심(center of mass, $\mathrm{COM}$ )의 이탈을 최소화하

Received Sep 15, 2015 Revised Oct 16, 2015

Accepted Oct 19, 2015

Corresponding author Jin-Hoon Park

E-mail jpark12@korea.ac.kr
며 신체안정성을 확보한다.,3 그리고 피드백은 신체의 동요를 겪은 후 에 감각 피드백 신호를 통해 $\mathrm{COM}$ 의 위치를 재배치하는 보상적 자세 적응(compensatory postural adjustment, $\mathrm{CPA}$ )이다. ${ }^{5}$

균형 능력을 평가하는 방법으로는 $\mathrm{COM}$ 의 변화를 관찰하는 방법 이 있다. ${ }^{6.7}$ 안정된 상태에서 $\mathrm{COM}$ 의 위치는 안정성의 한계점 내에 존 재하지만 균형에 어려움이 발생하게 되면 한계점 밖에 존재하게 되며 $\mathrm{COM}$ 은 신체 내에만 존재하는 것이 아니라 앞으로 숙여진 상태가 되 면 신체 밖에 존재하기도 한다. $\mathrm{COM}$ 이 신체 밖에 존재하더라도 균형 을 유지하기 위해 신체의 압력중심(center of pressure, $\mathrm{COP}$ )은 신체 내 에 존재해야 하며 $\mathrm{COP}$ 가 신체 밖으로 벗어나게 되면 안정성의 한계 에서 벗어나게 된다. 균형유지라는 것은 개인과 과제의 난이도 그리 고 지면의 형태 등에 따라 달라질 수 있다. ${ }^{8}$

균형을 안정적으로 유지하기 위해 필요한 주의(attention)는 정보처 리 능력으로 개인의 차이가 존재하고 과제의 특성에 따라 달리 사용 
된다는 것을 의미하며 이러한 주의를 분배하는 능력을 실행기능(executive function)이라고 한다. 실행기능은 목표 지향활동을 조직하고 경쟁과제 사이에서 주의를 분배하고 새로운 문제해결과제의 시작부 터 완료에 이르기까지 수행되는 복잡한 과정이라 할 수 있다. 실행기 능으로서 균형과 자세제어에 필요한 주의(attention)를 연구하는 방법 으로 일차과제(primary task)와 이차과제(secondary task)를 함께 수행 하는 이중과제 패러다임에 관심을 가지게 됐으며 이차과제로 인지과 제(cognitive task) 혹은 운동과제(motor task)의 수행을 통해 살펴볼 수 있다. 이러한 이중과제 패러다임은 두 가지 과제를 동시에 수행하여 전체 처리 능력 이상의 것이 요구되는 경우, 한쪽 혹은 양쪽 모두의 결과가 좋지 않을 수 있다고 보고되고 있다. ${ }^{10}$ 최근 연구들에서는 정 보처리를 위한 중추자원들의 경쟁으로 따른 수행력의 변화를 살펴 봄으로써 이중과제 수행이 인간의 자세제어와 균형에 중요한 변수임 을 확인하였으며, 특히 중추신경계의 문제로 인해 발생한 뇌졸중과 파킨슨환자들을 통해 일차과제와 이차과제의 수행을 통해 이차과제 의 형태와 난이도에 따라서 일차과제에 영향을 주고 있음을 확인하 였다.11,12

중추신경계에서 균형과 협응능력을 관할하는 것으로 알려져 있 는 소뇌는 감각수용기들로부터 유입되는 구심성 감각정보들을 일차 적으로 받아들이는 대표적인 신경구조체이다. 균형유지를 위한 사지 의 무의식적 구심성 감각정보는 배측 척수소뇌신경로(dorsal spinocerebellar tract)와 복측 척수소뇌신경로(ventral spinocerebellar tract)를 통해 소뇌로 유입되며 뇌줄기(brainstem)와 시상(thalamus)을 통하여 대뇌의 운동피질로 전달되어 사지의 움직임과 신체 협응을 조절하 는 과정에 관여를 한다. ${ }^{13}$ 균형과 자세제어에 중추적인 역할을 하는 소뇌의 병변이나 다른 원인에 의해 소뇌에 이상이 생기게 되면 자세 의 흔들림과 갑작스런 자세의 동요, 그리고 동요에 대한 과도한 반응, 관절과 관절간의 협응 장애, 체간의 비정상적인 동요, 신체의 전체적 인 흔들림 등이 발생하게 된다. 또한 복잡한 과제를 수행하거나 정밀 한 과제를 수행할 때 역시 정확성이 떨어지게 된다.14

선행 연구에 따르면 소뇌가 두 가지 이상의 동작을 수행함에 있어 이를 통합하고 전략을 수립하며 이를 실행에 옮기는 데 관여한다고 알려져 있다. ${ }^{5}$ 소뇌는 균형에서 제어적 역할을 할 뿐만이 아니라 주 의집중에 관여하고 주의를 분배하는 인지영역에서도 역할을 수행한 다. 소뇌는 움직임을 만들어 내기 위해 인지적 영역의 정보처리능력 인 주의 집중이 필요하고 이러한 주의를 분배하는 역할을 담당하는 인지적 영역과 주의를 분배하여 경쟁과제 사이에서 중요도에 따른 선택을 통해 움직임을 만들어내는 운동수행 역할까지 담당한다. ${ }^{16}$ 기 존의 연구들은 소뇌의 기능 중 균형과 자세제어 등을 포함한 운동학 적인 측면을 강조하여 연구되어져 오고 있다. 소뇌가 인지기능에 관 여한다는 연구는 부분적으로 이루어져 있기는 하지만 인지적 영역
과 운동학적 영역의 관계를 살펴본 연구는 아직까지 미흡한 실정이 다. 본 연구에서는 소뇌질환 환자를 대상으로 정적인 균형과 동적인 균형의 일차과제를 수행하면서 인지적 이차과제를 제시하여 소뇌질 환 환자들의 균형전략의 특성에 대해 알아보고자 한다.

\section{연구방법}

\section{1. 연구대상}

본 연구의 대상자들은 서울의 K 대학교 병원 신경과에 내원하여 유 전적 원인으로 인해 소뇌의 구조적 손상이 발생하는 소뇌위축증 (cerebellar atrophy) 진단을 받은 환자들을 대상으로 모집하였다. 본 연 구의 목적을 이해하고 자발적인 참가 의사를 밝힌 소뇌환자 중 8 명을 선별하였으며 (평균 나이 51.1세; 남자 4명, 여자 4명), 이들 중 뇌졸중 이나 종양 등으로 인해 소뇌의 특정 영역에 발생하는 국소성 병변(focal lesion)을 가진 자는 없었으며, 유전적 요인으로 인해 소뇌와 더불 어 일부 뇌간과 척수 영역에 걸쳐 신경세포가 광범위하게 사멸되는 퇴행성 질환으로 진단받은 환자들을 대상으로 연구를 진행하였다. 또한 실험에 앞서 한국형 간이 정신 상태 검사지(MMSE)를 통한 평가 에서 소뇌 이외의 중추신경계 문제로 인한 인지기능에 이상이 없는 지를 평가하여 치매와 같은 인지기능에 이상이 있는 참가자가 확인 될 시에는 연구 대상에서 제외시켰다. 그리고 의무 기록상 시력 그리 고 전정기관에 특별한 장애가 없는 상태이나 소뇌위축증 질환으로 인한 소뇌성 운동실조증을 가진 환자로 독립적인 균형이 가능한 환 자를 실험에 참여시켰다. 8 명의 대조군은 과거 병력이 없는 정상인으 로 연령과 성별을 동일하게 맞추었으며, 실험에 앞서 참가자들은 실 험에 참가하는 동의서를 작성하게 하였다.

\section{2. 실험설계}

본 연구의 실험설계는 이중과제와 단일과제로 구성되었다. 단일과제 는 일차과제 (자세제어)만 수행하였고, 정적서기 (정적균형), 좌우움 직임 (동적균형), 그리고 전후움직임 (동적균형)으로 이루어졌다. 이 중과제는 일차과제 (자세제어)와 이차과제 (인지과제)로 이루어졌으 며, 이차과제인 인지과제는 난이도에 따라 높은 난이도와 낮은 난이 도로 설정되었다. 실험은 소뇌환자 집단과 정상인 집단 모두 동일하 게 실험을 진행하였다.

\section{3. 실험절차}

본 연구에서는 균형제어시 운동학적 특성을 측정하기 위하여 OptiTrack (NaturalPoint Inc., Oregon, USA) 동작 캡처 프로그램을 사용하 였으며 실험을 위한 53 개의 마커가 부착된 수트를 입게 하였다. 수트 를 입은 상태의 정적 서기자세에서 피험자의 체간을 공간좌표 기준 
점을 원점 $(0,0,0)$ 으로 설정하였으며 신체의 좌. 우 방향을 $\mathrm{x}$ 축, 전. 후 방향을 $y$ 축, 상. 하 방향을 $\mathrm{z}$ 축으로 설정하여 자세 동요의 $\mathrm{COM}$ 을 측 정하였다. 동작에 대한 3D 좌표값은 Visual3D (C-Motion, Maryland, USA) 분석 프로그램을 사용하여 COM을 수치화하였다. 리드미컬한 동적 균형을 유도하기 위해 메트로놈(Micro Metronome Inc, USA)을 $24 \mathrm{bps}$ 와 16 beats로 사용하였다. 리드미컬한 속도를 나타내는 bps는 숫자가 올라갈수록 빨라진다. 소뇌환자는 동적균형에 어려움을 감 안하여 따라서 할 수 있는 느린 속도에 해당하는 $24 \mathrm{bps}$ 를 리드미컬 한 속도로 선정하였으며, 16 beats은 38초 동안에 움직이는 수치로서 동적균형을 하는 동안에 운동학적 데이터 수집이 가능한 수치로 설 정하였다.

실험도중 피험자의 피로도를 없애기 위해 각 단계별 휴식을 취하 게 하였다. 또한 이중과제로서 인지과제는 숫자를 일정한 간격으로 뺄셈을 하는 방식으로 실험 진행에 맞추어 수정된 스트룹 테스트 (stroop test)로 진행 하였으며 난이도 조절은 3 의 배수로 숫자를 빼나 갈 때를 낮은 난이도, 그리고 7의 배수로 빼나가는 것을 높은 난이도 로 설정하였다. ${ }^{17}$ 만약 시도 중에 5 문제를 틀리게 되면 100 에서부터 1 씩 빼나가는 것으로 난이도를 재수정하였으며 인지과제를 수행함에 있어 학습이 되는 것을 방지하기 위해 높은 난이도에서 인지과제 수 행을 잘할 경우, 100 이 아닌 99 , 내지는 102 등 무작위로 재수정하였으 며, 문제를 푸는 순서를 무작위로 설정하였다.

\section{4. 자료분석}

자료분석은 동작 캡처 프로그램을 이용하여 측정된 COM 자료를 Matlab (MathWorks Inc., Massachusetts, USA) 프로그램을 이용하여 $\mathrm{COM}$ 의 최댓값과 최솟값의 차이로 계산한 총 이동거리(displacement), 각 동작에서 $\mathrm{COM}$ 의 제어 안정성 변화의 크기를 표준편차로 평가한 가변성(variability) 그리고 COM 궤도를 미분하여 계산한 속 도(velocity)를 분석하였다. 그리고 분석결과는 SAS 통계 프로그램을 이용하여 평균과 표준편차를 산출하였다. 정적균형과 좌우 동적균 형에 대한 집단 (환자-통제집단) $\times 3$ 조건 (단일과제, 이중과제-높은 난 이도, 이중과제-낮은 난이도) Two-way ANOVA를 실시하였다. 사후검 증은 던컨의 다중범위검증(Duncan's Multiple-range test)을 통해 살펴 보았으며, 통계적 유의수준은 0.05 로 설정하였다.

\section{결 과}

\section{1. 정적균형 과제}

정적균형시 좌우방향(ML)에서 이중과제의 난이도에 따른 $\mathrm{COM}$ 의 간격 $[\mathrm{F}(2,30)=6.81, \mathrm{p}<0.05]$, 가변성 $[\mathrm{F}(2,30)=7.86, \mathrm{p}<0.05]$, 그리고 평균 속도 $[\mathrm{F}(2,30)=5.49, \mathrm{p}<0.05]$ 에서 통계적으로 유의하게 나타났다(Figure $1 \mathrm{~A}-\mathrm{C}$ ). 이차과제의 난이도가 낮은 조건에서는 집단 간 차이가 크 게 나타났으나 높은 난이도 조건에서는 집단 간 차이가 나타나지 않
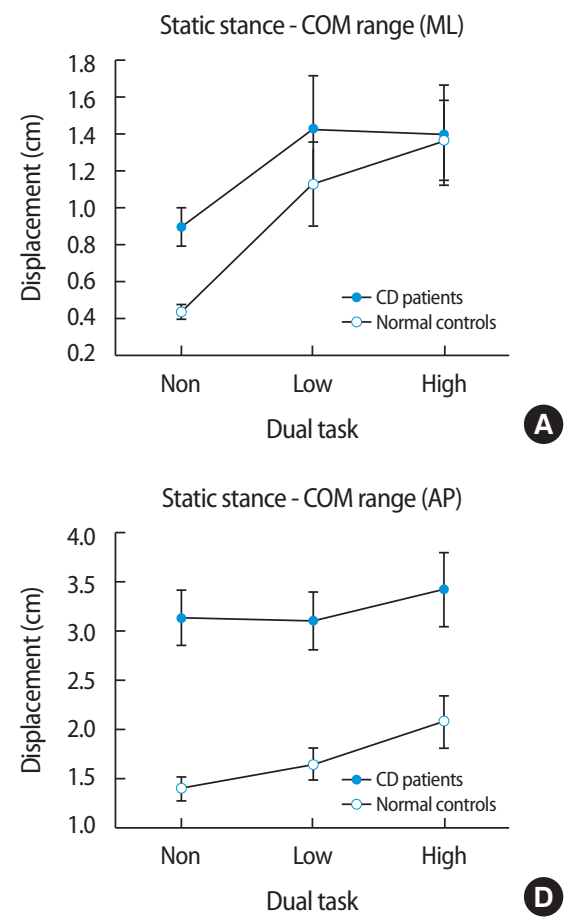

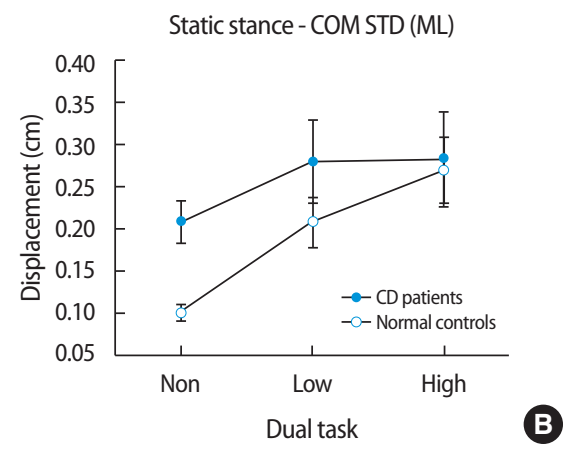

Static stance - COM STD (AP)

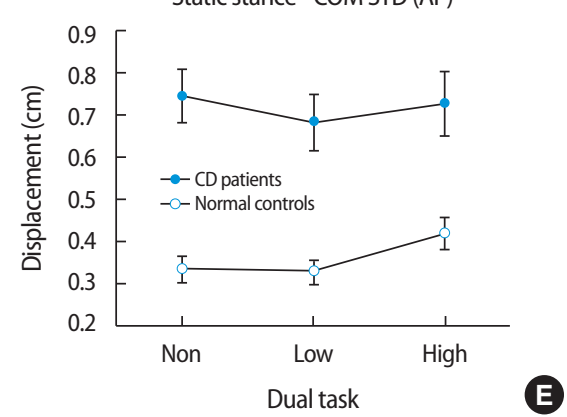

Static stance - COM velocity (ML)

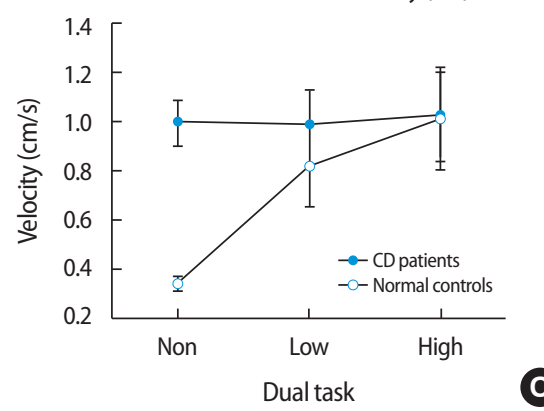

Static stance - COM velocity (AP)

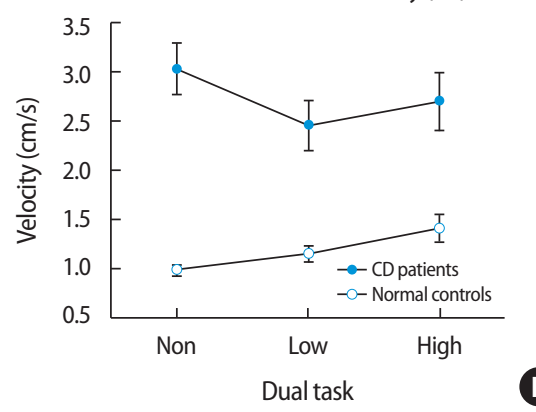

Figure 1. The average and the standard error of center of mass (COM) displacement (A), variability of COM (B), and velocity (C) in the medio-lateral $(\mathrm{ML})$ direction, COM displacement $(\mathrm{D})$, variability of $\mathrm{COM}(\mathrm{E})$, and velocity $(\mathrm{F})$ in the anterio-posterior $(\mathrm{AP})$ direction in the static stance task condition. 
았다. 정적균형시 전후방향(AP)에서 소뇌환자집단과 정상인 집단 간 의 차이에서는 $\mathrm{COM}$ 의 간격 $[\mathrm{F}(1,11)=10.41, \mathrm{p}<0.05]$, 가변성 $[\mathrm{F}(1,11)$ $=11.34, \mathrm{p}<0.05]$, 그리고 평균속도 $[\mathrm{F}(1,1)=12.68, \mathrm{p}<0.05]$ 에서 유의하게 나타났으며, $\mathrm{COM}$ 의 평균속도에 대한 집단과 과제 간의 상호작용효 과 역시 통계적으로 유의하게 나타났다[F(2,22)=4.37, $\mathrm{p}<0.05]$ (Figure 1D-F).

\section{2. 좌우 동적균형 과제}

좌우 동적균형시 좌우방향(ML)에 대한 $\mathrm{COM}$ 의 간격 $[\mathrm{F}(1,11)=16.23$, $\mathrm{p}<0.05]$, 가변성 $[\mathrm{F}(1,11)=18.99, \mathrm{p}<0.05]$, 그리고 평균속도 $[\mathrm{F}(1,1)=11.20$, $\mathrm{p}<0.05]$ 에 대해 집단 간의 차이가 통계적으로 유의하게 나타났다 (Figure 2A-C). 그리고 소뇌환자집단과 정상인 집단 모두에서 이중과 제의 난이도에 따른 통계적 유의차이가 나타났다 $[\mathrm{F}(2,30)=6.82$, $\mathrm{p}<0.05$ ]. 좌우 동적균형시 전후방향(AP)에서 집단 간의 차이가 나타 나지 않았고, 난이도에 따른 과제 간의 차이 역시 경향성은 나타났으 나 유의한차이가 나타나지 않았다(Figure 2D-F).

\section{3. 전후 동적균형 과제}

전후 동적균형시 좌우방향(ML)에서 나타난 결과에서는 이중과제의 난이도에 따른 간격 $[\mathrm{F}(2,30)=5.74, \mathrm{p}<0.05]$ 과 가변성 $[\mathrm{F}(2,30)=6.39$, $\mathrm{p}<0.05]$, 그리고 평균속도 $[\mathrm{F}(2,30)=5.08, \mathrm{p}<0.05]$ 에서 통계적 유의차 이가 나타났다(Figure 3A-C). 이차과제의 난이도가 낮은 조건에서는
집단 간 차이가 나타나지 않았으나, 높은 난이도 조건에서는 집단 간 차이가 나타났다. 전후 동적균형시 전후방향(AP)에서 COM의 가변 성에서 집단 간의 차이 $[\mathrm{F}(1,11)=8.34, \mathrm{p}<0.05]$ 가 통계적으로 유의하게 나타났으며, 또한 이중과제의 난이도에 따른 차이 $[\mathrm{F}(2,30)=4.25$, $\mathrm{p}<0.05]$ 역시 통계적으로 유의하게 나타났다. 그리고 평균속도에 대 한 집단 간의 차이 $[\mathrm{F}(1,11)=5.98, \mathrm{p}<0.05]$ 와 과제 간의 차이 $[\mathrm{F}(2,30)=$ $4.20, \mathrm{p}<0.05$ ]가 나타났다(Figure 3D-F).

\section{4. 동적균형 시 좌우방향(ML)과 전후방향(AP)의 영점교차점과 정체시간}

동적균형시 COM의 영점교차점(zero-crossings)에 대한 집단과 과제 간의 상호작용에서 통계적으로 유의하게 나타났다 $[\mathrm{F}(2,22)=6.39$, $\mathrm{p}<0.05]$ (Figure 4A). 동적균형 시 COM의 정체시간(dwell time)에서는 이중과제의 난이도에 따른 과제 간의 차이는 유의하게 나타났다 $[\mathrm{F}(2,30)=4.22, \mathrm{p}<0.05]$. 사후검증결과 과제 간의 차이는 낮은 난이도 과제와 높은 난이도 과제 조건에서 차이가 있는 것으로 나타났다 (Figure 4B).

\section{고 찰}

\section{1. 이중과제가 정적균형에 미치는 운동학적 특징}

정적균형상태에서 좌우방향(ML)을 살펴보면 신체무게중심(COM)

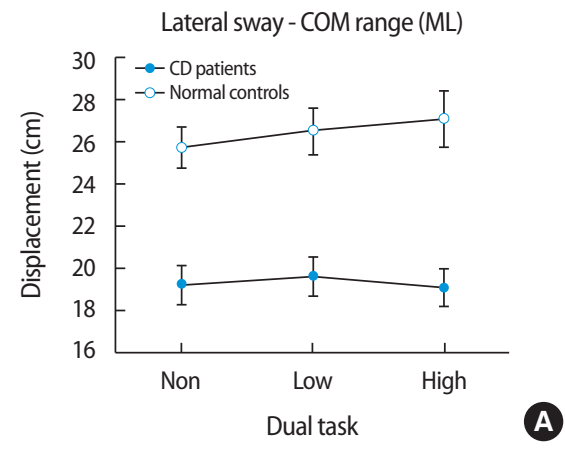

Lateral sway - COM range (AP)

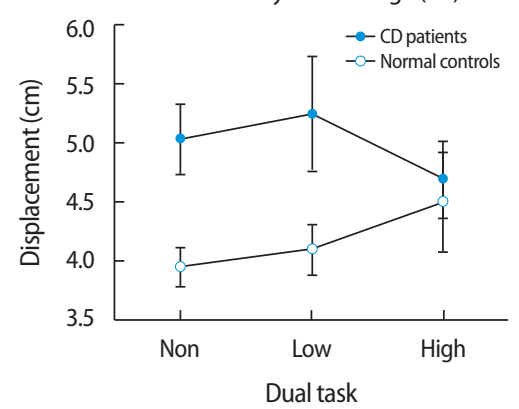

Lateral sway - COM STD (ML)

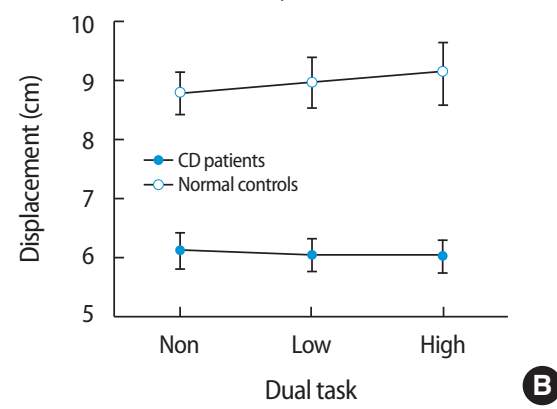

Lateral sway - COM STD (AP)

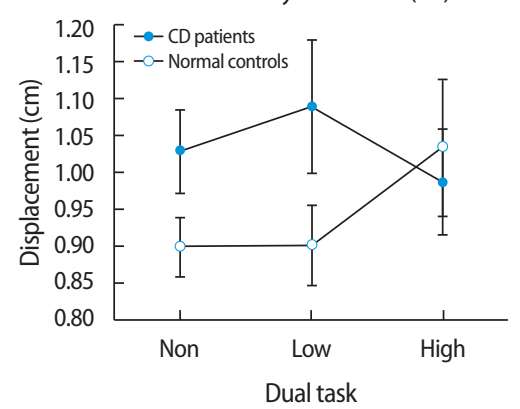

Lateral sway - COM velocity (ML)

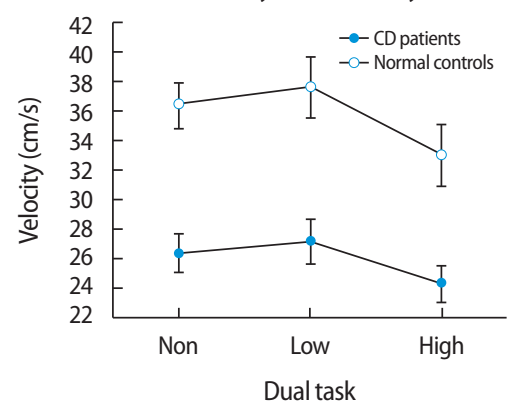

Lateral sway - COM velocity (AP)

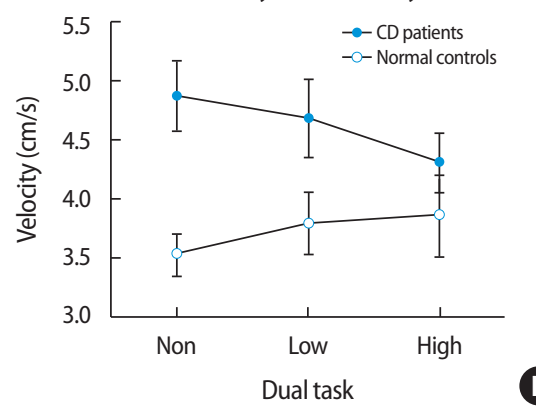

Figure 2. The average and the standard error of COM displacement (A), variability of COM (B), and velocity (C) in the medio-lateral (ML) direction, COM displacement (D), variability of COM (E), and velocity (F) in the anterio-posterior (AP) direction in the lateral sway task condition. 


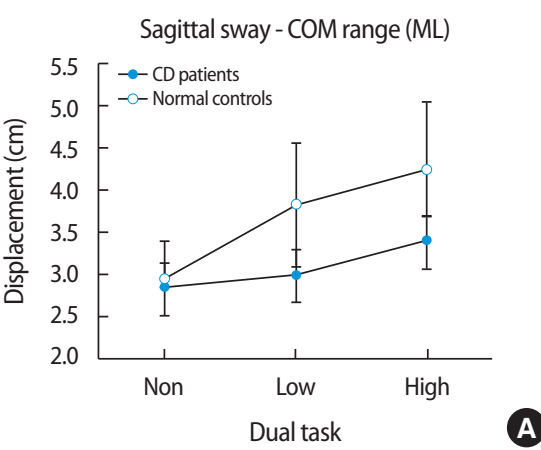

Sagittal sway - COM range (AP)

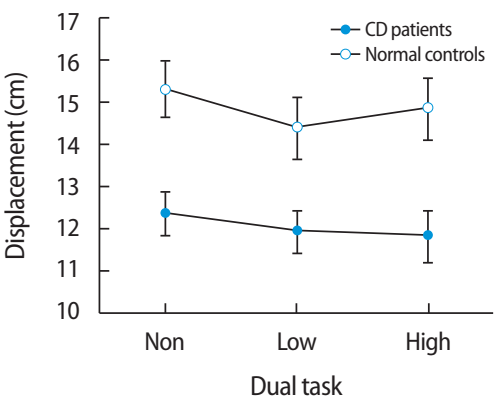

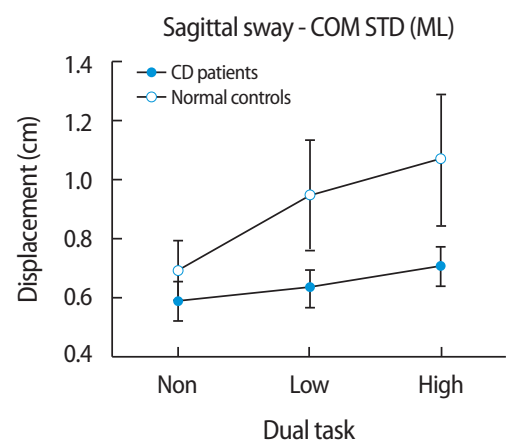

Sagittal sway - COM STD (AP)

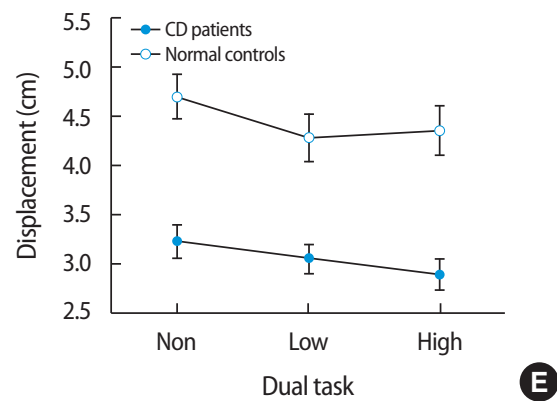

Sagittal sway - COM velocity (ML)

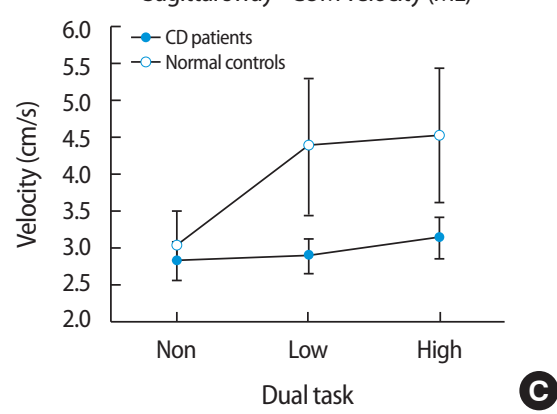

Sagittal sway - COM velocity (AP)

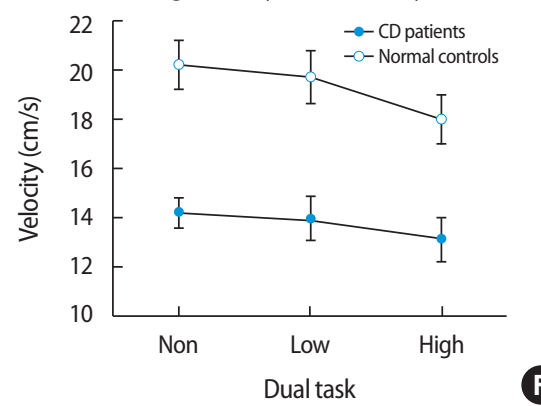

Figure 3. The average and the standard error of COM displacement (A), variability of COM (B), and velocity (C) in the medio-lateral (ML) direction, COM displacement (D), variability of COM (E), and velocity (F) in the anterio-posterior (AP) direction in the saggital sway task condition.
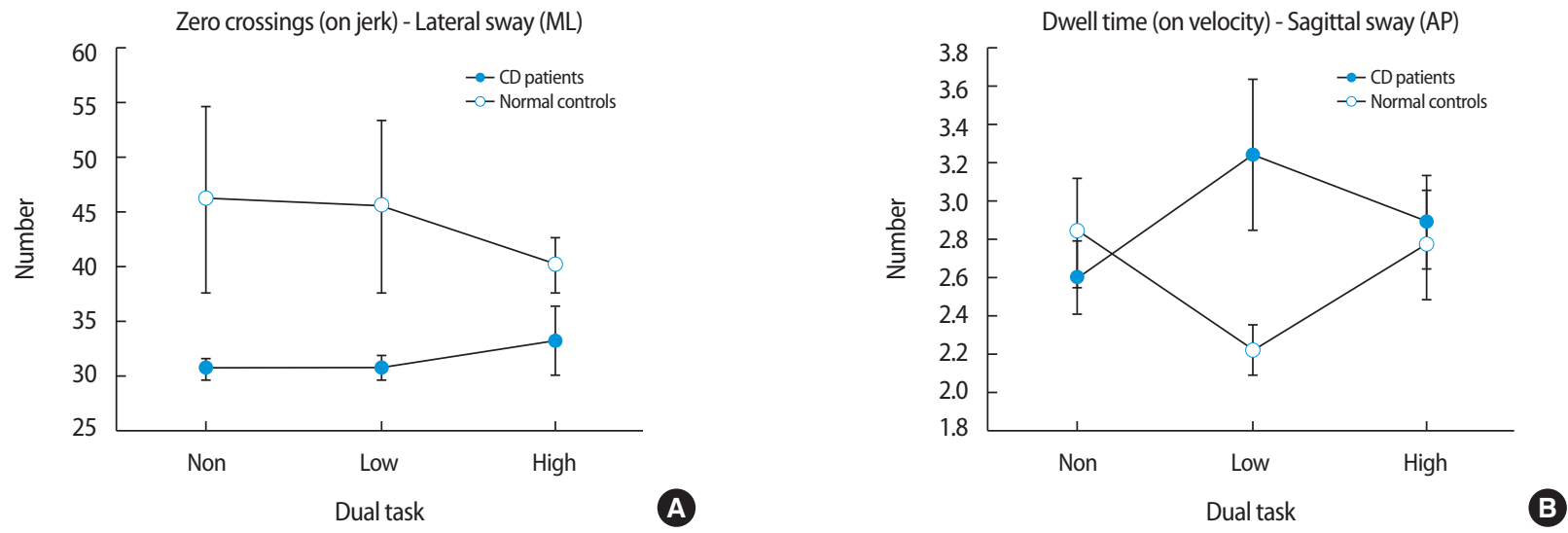

Figure 4. The average and the standard error of COM zero crossings in the lateral sway task condition (A) and dwell time in the saggital sway task condition (B).

의 움직인 간격과 가변성, 그리고 평균속도에 대한 소뇌환자와 정상 인 집단 간의 차이는 나타나지 않았다. 이러한 결과가 의미하는 바를 신체의 안정성 한계의 측면에서 살펴보면 소뇌환자와 정상인의 경우 좌우방향(ML)에 대해 편안하게 양발을 벌린 상태에서 정적균형을 수행하여 양발이 넓어진 폭만큼 신체 안정성의 한계가 증가하였고 보간의 폭만큼 지지기저면이 넓어짐으로써 자세를 유지하는 데 용이 해져 소뇌환자집단과 정상인 집단 간의 차이가 나타나지 않은 것으 로 보인다. Nashner ${ }^{18}$ 의 연구에 의하면 일반인의 경우의 신체 안정성 한계치는 전후 동요 한계치는 발을 $10 \mathrm{~cm}$ 정도 벌린 상태에서 최고 앞
으로 기울어진 자세에서 최고 뒤로 기울어진 자세까지 12 도 이내이 며 좌우 동요 한계치는 양발이 지지된 상태에서 외측 끝 기울기에서 반대쪽 끝 기울기까지 16 도 이내에서 신체 안정성을 확보할 수 있다 고보고하였다.

정적자세를 유지하는 동안에 소 뇌환자의 경우 $\mathrm{COM}$ 의 간격변화 에서 전후방향(AP)이 정상인의 집단에 비해 동요가 크게 증가하였 다. 소뇌환자의 경우 정상인들에 비해 $\mathrm{COM}$ 의 전후로 흔들림이 많은 이유는 병인학적 원인으로 인해 균형에 어려움이 증가하게 된 것으 로 보이며, Morton과 Bastian ${ }^{17}$ 의 연구에 의하면 소뇌환자들은 정상 
인들에 비해 신체 움직임의 동요가 크게 증가하였고 움직임의 최고 속도가 증가하여 더 많은 신체동요가 나타났고 전후로 흔들림이 정 상인들에 비해 더 크게 나타났다고 보고하였다. 선행연구에서 Winter 등이 정상인들을 대상으로 정적서기, 전후, 그리고 좌우의 신체 동요를 비교한 연구에서 좌우 흔들림에 비해 전후의 흔들림이 크게 나타난 선행연구의 결과와 일치하며 발목관절과 무릎관절의 구조와 근육들이 많이 사용되어 전후의 흔들림이 더 많이 나타난다고 하였 다. 그리고 정적으로 서 있는 경우에도 미세한 움직임이 나타나거나 전후로 흔들림이 나타난다는 연구와 정상인을 대상으로 한 연구에 서 좌우의 흔들림보다 전후의 흔들림이 더 많이 나타난 결과와도 일 치한다. ${ }^{19}$ 따라서 흔들림에 의한 보상적 자세를 앞쪽과 뒤쪽으로 움직 이면서 균형을 유지하려고 한 것으로 보이며 이는 낙상을 예방하기 위한 전략으로 보인다.

소뇌성 운동실조증 환자들의 경우, 정적균형에서 이차과제와는 상관없이 일차적 과제인 균형에 어려움이 계속적으로 나타났다. 전 후방향(AP)으로 많이 흔들린 것은 이중과제에 대한 주의집중이 높아 짐에도 불구하고 소뇌환자들의 정적균형에 어려움이 존재하는 것은 소뇌 손상으로 인한 균형제어에 어려움이 있는 것으로 풀이된다. 하 지만 고령인의 연구에서는 이중과제시 자세제어에 어려움을 겪으며 과제의 난이도가 높아짐에 따라 균형에 어려움이 증가한다는 결과 와는 상반된다. ${ }^{20}$ 그리고 Yardley 등도도 이중과제와 자세제어와의 관 계를 알아보기 위해 인지과제를 빠르면서 정확하게 하도록 한 결과에 서도 이중과제시에 자세동요가 증가한 연구결과와도 상반된다. 이중 과제의 난이도가 증가하게 되면 동요의 발생이 커지게 되며 자세의 안정성이 결여된다는 다른 결과와는 달리 소뇌환자들은 이중과제의 난이도가 없는 단일과제에서도 $\mathrm{COM}$ 의 변화가 크게 나타난 것은 이 중과제의 유무와는 상관없이 균형제어에 어려움을 항상 겪는다는 것을 직접적으로 나타낸다고 볼 수 있다. 정적균형에 대해 소뇌환자 들이 좌우방향(ML)에서 $\mathrm{COM}$ 의 움직인 간격이 미세하게 나타난 것 은 균형에 어려움이 존재하기는 하지만 지지기저면이 넓게 형성되어 안정적 자세유지가 가능한 것으로 보인다. 전후방향(AP)에서 $\mathrm{COM}$ 의 움직인 간격이 큰 것은 낙상을 예방하기 위한 전략이기도 하지만 낙 상이 전후면으로 많이 일어난다는 것을 재확인할 수 있었다.

\section{2. 이중과제가 동적균형에 미치는 운동학적 특징}

이중과제를 수행하는 동안 동적균형에 나타난 좌우방향(ML)의 결 과를 살펴보면 소뇌환자의 경우 정상인 집단에 비해 좌우 동적균형 에 있어서 $\mathrm{COM}$ 의 움직인 간격 범위가 상대적으로 좁게 나타난 것을 확인할 수 있었다. 소뇌는 균형에 필요한 사지의 수의적 움직임 조절, 운동 수행을 위한 주동근(agonist)과 길항근(antagonist)의 근육 협응, 또한 근육의 긴장도를 조절하여 신체의 정적 및 동적 균형을 유지하
는 운동학적 기능을 한다. ${ }^{22} \mathrm{COM}$ 의 간격이 좁아지고 평균속도가 감 소한 것은 소뇌 손상으로 인해 수의적 움직임 조절장애, 근협응장애, 그리고 근 긴장도 조절장애로 인한 불안정한 자세를 극복하기 위해 소뇌환자들이 소극적 움직임을 취함으로써 낙상을 예방하고 균형을 유지하려는 전략으로 보인다. 그 뿐만 아니라 소뇌는 근육의 긴장도 를 조절하여 신체의 정적 및 동적 평형을 유지하는 중요한 역할을 하 는데 소뇌환자들은 소뇌의 손상으로 인하여 근육 및 관절과 관절 사 이의 협응 조절과 신체의 균형을 유지하는 데 어려움이 있기 때문에 동적인 움직임에서 $\mathrm{COM}$ 의 간격이 좁아지고 평균속도가 감소하는 것은 신체움직임을 최소화하는 소극적 자세를 취함으로써 균형을 유지하여 낙상을 예방하기 위한 전략을 선택한 것이라고 볼 수 있다. 고령인을 대상으로 한 Benjuya 등 23 의 연구 결과를 보면 이중과제와 정적서기를 동시에 수행하는 경우에 고령인들은 근육을 긴장시키는 전략을 통해 자세제어를 유지하고 하지의 움직임을 최소화하여 움 직이지 않는 동결상태(freezing)를 이용한 전략을 통해 균형을 유지하 려고 노력한다는 결과와도 일치한다. 또한 소뇌환자들에게 나타나 는 운동학적 특징 중의 하나인 운동반복장애는 전체적인 움직임의 맥락에서 분리되는 현상처럼 보이는 것을 의미하며 단속적으로 끊 어져 부자연스러운 움직임처럼 보이는 장애로 리드미컬하게 움직이 는 동적균형을 행하는 과제에서 어려움을 겪었다. 소뇌의 운동학적 영역에서 소뇌의 내측 중심영역은 사지의 방향과 적절한 타이밍, 힘 조절 등과 관계된 역할을 담당하는데 좌우로 대칭적 반복적 리듬에 맞추어 이루어지는 균형과 반복적 운동을 하는 데 있어 소뇌환자들 이 어려움을 겪은 것은 소뇌의 역할이 균형과 자세제어에 관여한다 는 것을 다시 확인시켜 준 결과라 할 수 있다.

자세제어와 균형을 위한 감각정보처리를 피드포워드(feedfoward) 와 피드백(feedback)의 관점에서 살펴보면 정상인인 경우에 신체 안정 성의 한계를 벗어나지 않은 상태에서의 작은 움직임은 자동적으로 이루어지고 있는 자세제어시스템에 영향을 크게 받지 않으며 동요나 변화가 발생한 후에 감각 피드백 신호를 통해 보상적 자세적응으로 신체 무게중심의 위치를 재배치하는 기전으로 자세제어가 가능하다 는 것을 보여준다. 하지만 소뇌환자들은 균형과 자세제어에 어려움 이 있기에 정적균형과 동적균형에서 예상되는 자세동요변화를 예측 하여 반응하는 예비적 자세적응으로 신체 무게중심의 이탈을 최소 화하는 피드포워드 관점에서 균형을 유지하는 것으로 보인다.

결론적으로 소뇌성 운동실조증 환자들은 이중과제의 난이도가 높아질수록 신체 무게중심의 속도와 위치의 가변성에 차이가 많이 나타났으며, 소뇌성 운동실조증 환자들은 정상인과 비교하였을 때 신체 무게중심의 속도와 위치의 가변성이 차이가 크게 나타났다. 그 리고 소뇌성 운동실조증 환자들은 정적균형과 동적균형에서 신체 무게중심의 속도와 위치의 가변성이 동적균형에서는 작게 나타난 반 
면, 정적균형에서 상대적으로 크게 나타났다. 이는 정상인에게서 자 동적으로 이루어지는 자세제어와는 달리 소뇌환자들의 정적자세와 동적균형을 유지하는 상태에서 COM 간격이 줄어든 것은 낙상을 예 방하고 스스로 보호하기 위해 최우선적으로 자세를 안정시키는 멈 춤전략, 즉 균형을 유지하기 위한 방어적 운동전략을 선택한 것으로 보인다. 본 연구의 결과는 소뇌 질환으로 인해 발생하는 균형 장애에 대한 정확한 임상적 진단과 그 진행에 따른 특성을 운동행동학적으 로 검증하는 유용한 기초적 자료를 제공하고, 체계적이고 특별한 치 료법의 부재로 어려움을 겪는 소뇌성 운동질환 환자들의 효과적인 치료적 운동재활법의 개발에 도움이 되는 자료가 될 것이다.

\section{ACKNOWLEDGEMENTS}

This research was supported by the College of Education, Korea University Grant in 2015.

\section{REFERENCES}

1. Shumway-Cook A, Woollacott MH. Motor control: Theory and practical application. 2nd ed. Baltimore, Williams \& Wilkins, 2001:197-228.

2. Manchester D, Woollacott M, Zederbauer-Hylton N et al. Visual, vestibular and somatosensory contributions to balance control in the older adult. J Gerontol. 1989;44(4): M118-M27.

3. Kim JH. Relationship between gait symmetry and functional balance, walking performance in subjects with stroke. J Kor Phys Ther. 2014; 26(1):15-20.

4. Aruin AS, Latash ML. The role of motor action in anticipatory postural adjustments studied with self-induced and externally triggered perturbations. Exp Brain Res. 1995;106(2):291-300.

5. Chae YW, Park JW, Park s. Effects of knee malalignment on static and dynamic postural stability. J Kor Phys Ther. 2015;27(1):7-11.

6. Horak FB, MacPherson JM, Peterson BW. Postural orientation and equilibrium. New York, Published for the American Physiological Society by Oxford University Press, 1996.

7. Winter DA, Prince F, Frank JS et al. Unified theory regarding A/P and M/L balance in quiet stance. J Neurophysiol. 1996;75(6):2334-43.
8. Yang DJ, Park SK, Kang JI et al. Effects of changes in postural alignment on foot pressure and balance of patients with stroke. J Kor Phys Ther. 2014;26(6):226-33.

9. McCollum G, Leen TK. Form and exploration of mechanical stability limits in erect stance. J Mot Behav. 1989;21(3):225-44.

10. Song HS, Kim JY. Clinical feasibility of mental practice for gait ability improvement of Parkinson disease patients: ABA single subject design. J Kor Phys Ther. 2014;26(6):398-402.

11. Lee KS, Kim K, Lee NK. The effects of lower limb training using sliding rehabilitation machine on the foot motion and stability in stroke patients. J Kor Phys Ther. 2015;27(1):24-9.

12. Bensoussan L, Viton JM, Schieppati M et al. Changes in postural control in hemiplegic patients after stroke performing a dual task. Arch Phys Med Rehabil. 2007;88(8):1009-15.

13. Morris M, Iansek R, Smithson F et al. Postural instability in Parkinson's disease: a comparison with and without a concurrent task. Gait Posture. 2000;12(3):205-16.

14. Morton SM, Bastian AJ. Cerebellar contributions to locomotor adaptations during splitbelt treadmill walking. J Neurosci. 2006;26(36):9107-16.

15. Kwon YH, Kim CS. Comparison of Motor Function and Skill between Stroke Patients with Cerebellar and Non-cerebellar Lesion in Sub-acute. J Kor Phys Ther. 2012;24(6):423-27.

16. Inhoff AW, Diener HC, Rafal RD et al. The role of cerebellar structures in the execution of serial movements. Brain. 1989;112(3):565-81.

17. Morton SM, Bastian AJ. Cerebellar control of balance and locomotion. Neuroscientist. 2004;10(3):247-59.

18. Nashner LM. Fixed patterns of rapid postural responses among leg muscles during stance. Exp Brain Res. 1977;30(1):13-24.

19. Horak FB, Nashner LM. Central programming of postural movements: adaptation to altered support-surface configurations. J Neurophysiol. 1986;55(6):1369-81.

20. Pellecchia GL. Postural sway increases with attentional demands of concurrent cognitive task. Gait Posture. 2003;18(1):29-34.

21. Yardley L, Gardner M, Lavie N et al. Attentional demands of perception of passive self-motion in darkness. Neuropsychologia. 1999;37(11): 1293-301.

22. Morton SM, Bastian AJ. Relative contributions of balance and voluntary leg coordination deficits to cerebellar gait ataxia. J Neurophysiol. 2003; 89:1844-56.

23. Benjuya N, Melzer I, Kaplanski J. Aging-induced shifts from a reliance on sensory input to muscle cocontraction during balanced standing. J Gerontol A Biol Sci Med Sci. 2004;59(2):M166-M71. 